\title{
EL ESTATUS MULTIPARADIGMÁTICO DE LA PSICOLOGÍA
}

\section{THE ESTATUS MULTIPARADIGMÁTICO OF PSYCHOLOGY}

\section{MANUEL CAMPOS ROLDÁN ${ }^{1}$}

Universidad Nacional Mayor de San Marcos, Facultad de Psicología

\section{RESUMEN}

El trabajo examina el estado multiparadigmático de la psicología contemporánea en nuestro medio. Se revisa los conceptos epistemológicos de ciencia, ideología, modelo teóricometodológico y paradigma.

Palabras clave: Epistemología, metodología, ciencia, ideología, paradigma.

\begin{abstract}
The paper examines the paradigmatic situation in contemporary Psychology. It reviews science, ideology, model and paradigm as epistemological concepts.
\end{abstract}

Keywords: Epistemology, Methodology, Science, Ideology, Paradigm.

\footnotetext{
${ }^{1}$ Profesor Asociado de la Facultad de Psicología UNMSM. Psicólogo. Magíster en Filosofía.
} 


\section{INTRODUCCIÓN}

\section{La unidad teoría-investigación}

Refiriéndose a la importancia de disponer de teorías para llevar cabo investigaciones, el psicólogo alemán Kurt Lewin (18901947) formularía este elocuente juego de palabras: "nada hay más práctico que una buena teoría». Empero, quienes lo recuerdan ignorarían u obviarían que Lewin no dejó ahí la frase, pues seguidamente acotaría que: "una teoría que sólo produce libros no es suficiente» (Clemente y Molero, 1994: 846) ${ }^{1}$.

Este último es un juicio taxativo respecto de la ciencia fáctica. Más exactamente, de ciencias sociales como psicología, donde la teoría no juega el papel prominentemente especulativo que tiene en ciencias humanas como la filosofía o la literatura (ciencias en las cuales lo hermenéutica o interpretativo prima sobre lo heurística). Una teoría fáctica carente de medios empíricos o prácticos de corroboración deviene intrascendente. A la inversa, es inconcebible una investigación empírica sin una hipótesis siquiera implícita. La filosofía y su historia respaldan largamente la unidad teoría-praxis.

Por ejemplo, Platón (aprox. 428-347 a. C) pone en boca de Menón esta pregunta dirigida a su maestro: ¿Y de qué manera vas a investigar, Sócrates, lo que no sabes en absoluto qué es? Porque ¿qué es lo que, de entre cosas que no sabes, vas a proponerte como investigación? O, Aun en el caso favorable de que lo descubras, ¿cómo vas a saber que es precisamente lo que tú no sabías?» (Fernández, 1974: 101)². A su vez, Immanuel Kant (1724-1804) pondría en su sitio a la observación y el entendimiento. Sin la primera no podemos captar directamente las cosas, pero sin el entendimiento no podemos pensar sobre lo que vemos: "Pensamientos sin contenido, son vacíos; intuiciones sin concepto, son ciegas», decía (Kant, 1781/1979, 1: 202) ${ }^{3}$. Por tanto, el propósito fundamental del presente informe es demostrar la relación de consecuencia entre la teoría y la praxis en el estatus pluriparadigmático que ostenta en la actualidad la psicología académica y profesional. El trabajo tendrá dos partes:

1. El concepto de paradigma: Revisión y propuesta de definición; y

2. Modelos teóricos, metodológicos y técnicos como paradigmas psicológicos.

\section{Paradigma: Revisión y propuesta conceptual}

El término "paradigma» tiene antecedentes remotos. En Platón, paradigma es imagen o modelo representativo de las Ideas, modelo que debe mirarse al momento de hacer algo. El alemán Albrecht von Bollstadt, es decir, Alberto Magno (1193-1280) escribió que esta palabra reunía dos voces griegas: $\pi \alpha \rho \alpha$ (para), «al lado de», y $\delta \gamma \mu \alpha$ (digma), «lo que enseña» (Fernández, 1989, II: 159) ${ }^{4}$. En consecuencia, equivaldría a "lo que enseña por medio de lo que está al lado».

Esta historia de la palabra "paradigma» permitiría situar el concepto respectivo como sinónimo de esquema. Un esquema, siguiendo la definición de Rumelhart (citado por Leahey y Harris, 1998: 218) ${ }^{5}$, funcionaría como una teoría que guía interpretaciones y fundamenta predicciones empíricamente contrastables, como analizador sintáctico que recepta, organiza e interpreta datos de entrada.

En este trabajo defino paradigma psicológico como la fracción de la comunidad profesional de los psicólogos que comparte:

1. Un esquema teórico-explicativo sobre los determinantes del comportamiento como tema de estudio psicológico;

2. Un esquema metodológico de investigación coherente con el enfoque teórico para dar cuenta de problemas teóricos e hipótesis empíricas; y 
3. Un conjunto de aplicaciones técnicas acordes con (1) y (2) para la resolución de los problemas prácticos propios del ámbito de estudio elegido.

En tanto subdivisión de la comunidad de profesionales, un paradigma deviene en sistema socio-epistémico cuyos miembros comparten una suerte de esquema-plantilla, el cual articula y conduce las interpretaciones, predicciones y estrategias de intervención.

Un paradigma consta de un esquema teórico-explicativo. Veremos, por tanto, un esbozo del conocimiento científico.

\subsection{Teoría y estructura del lenguaje científico-fáctico:}

Según una teoría del vocabulario científico-fáctico, éste se divide en lenguaje observacional $\left(\mathrm{L}_{\mathrm{o}}\right)$ y lenguaje teórico $\left(\mathrm{L}_{\mathrm{t}}\right)$. $\mathrm{L}_{\mathrm{o}}$ consta de términos que designan eventos o propiedades y relaciones observables. Su función es descriptiva. $\mathrm{L}_{t}$ consta de términos referidos a eventos o características inobservables de los eventos. La función de $\mathrm{L}_{\mathrm{t}}$ es explicativa.

El término «cerebro», por ejemplo, pertenece a Lo: designa un órgano que puede observarse dentro del cráneo. Pero la palabra «pensamiento», no: al mirar la superficie e interior del cerebro no se ve lo que la persona piensa. Luego, es un término de $\mathrm{L}_{\mathrm{t}}$. Esto plantea un problema lógico y ontológico: ¿cuáles son los referentes de los términos de la psicología? Respondamos la pregunta con el materialismo contextualista y ficcionista.

Los términos científicos expresan conceptos. Para el materialismo, los conceptos son separables de su codificación lógicolingüística; su significado lo determina su uso al interior de contextos teóricos: personalidad e inteligencia existen en psicología, no en biología. El ficcionismo afirma que los referentes de los conceptos psicológicos existen convencionalmente. El proceso mental es una abstracción de la observación: las teorías psicológicas describen los procesos mentales como si de hecho se dieran (Bunge, 1980: 50$51)^{6}$. No discernir esto es no distinguir la dimensión pragmática del lenguaje.

Los conceptos científicos pueden ser cualitativos, comparativos o métricos. Los primeros designan clases (introvertido, extrovertido) y sirven a fines descriptivos. Si se busca explicar una conducta, el concepto cualitativo es insuficiente y circular: decir que alguien es insociable porque es introvertido no es explicar. Explicar algo es decir por qué ocurre; y esto se formula mediante enunciados condicionales de la forma: «x '! y», donde x es una «variable independiente», un estímulo externo al sujeto cuya conducta se estudia, e y es una «variable dependiente», una medida de la conducta de dicho sujeto. El enunciado «x '! y" equivale a «y porque $x »$. Es decir, la explicación científica sirve a la predicción $y$, por derivación lógica, a la prevención.

Los conceptos comparativos definen diferencias de grado: una persona puede ser más o menos depresiva que otra; un alumno puede tener vocación para ingeniería antes que para economía; un aspirante a un puesto en una organización puede mostrar mayor capacidad para el trato con personas que otro, etc. El concepto comparativo permitirá la introducción ulterior de conceptos métricos, también llamados conceptos cuantitativos o magnitudes. Para delimitar los conceptos métricos distingamos entre metrización y medición. Metrización es el procedimiento de asociación de valores numéricos a conceptos. Por su parte, la medición asigna números a conductas. La metrización antecede a la medición: para medir debe haber un concepto métrico. Concepto métrico es el que asocia valores numéricos a segmentos de conducta. Conceptos métri.cos son inteligencia, personalidad y actitud. 


\subsubsection{El (seudo) dilema cuantitativo cualitativo:}

La investigación empírica estudia hechos. Éstos se representan mediante datos. Un dato es un enunciado que informa y registra el resultado observado de una operación de investigación, de una intervención profesional o la ocurrencia de un evento. No es algo dado, sino construido en enunciados básicos u observacionales. Posee «referencia objetiva» pues la observación que reporta nada tiene que ver con la experiencia personal del investigador. A fortiori, es un enunciado cuya veracidad es replicable.

La observación puede ser di recta o indirecta. Es directa si los acontecimientos ocurren ante la mirada y registro del observador; indirecta, en el caso del uso de pruebas psicológicas o de técnicas de neuroimagen. En cada caso, el dato es interpretable. Hay dos clases de datos: a) datos cuantitativos; y b) datos cualitativos. Los datos cuantitativos suelen presentarse en dos formas. Pueden representarse en enunciados que describen puntuaciones o en enunciados que formulan conclusiones basadas sobre aquéllas. Aquí interesa el cuánto de los datos. Dicho brevemente, interesa saber cuánto difieren las puntuaciones entre sí.

Los datos cualitativos, por su parte, presentan percepciones subjetivas obtenidas en entrevistas, estudios de caso, de campo y observación participante. La investigación que reúne datos cualitativos no se interesa en cuánto varían las distribuciones ni infiere causal mente de puntuaciones estadísticamente analizadas. Se interesa en la percepción y el significado que las personas le dan a las condiciones que enfrentan. Dicha percepción y significado se expresan en enunciados que como tales constituyen datos cualitativos.

La polémica respecto de la supremacía de lo cuantitativo o lo cualitativo estaría pasando por alto que sólo habría dos métodos: a) métodos experimentales; y b) métodos noexperimentales.

Método experimental es modelo de variación y constancia (O'Neil, 1968: 31) ${ }^{7}$ : una variable independiente activa (VI) obra en poder del investigador, quien la aplica sólo a un grupo (el grupo experimental) respecto de una variable dependiente (VD) y observa el efecto sobre esta última a través de una medida de conducta. Hay un grupo de comparación al que no se aplicará la VI y cuyo comportamiento se confronta con el grupo experimental: el grupo control; con éste se mantienen constantes las condiciones de estudio.

$\mathrm{O}^{\prime} \mathrm{Neil}^{7}$ trata con sencillez los métodos no experimentales, de los que es parte la obtención de datos cualitativos. El objetivo de los métodos no-experimentales es el establecimiento de hechos representativos (O'Neil, 1968: 50) ${ }^{7}$. Es decir, se destinan exclusivamente a mostrar en qué estado se hallan las condiciones que se pretende estudiar. Su finalidad es, pues, propiamente descriptiva. De modo que, si se desea llevar a cabo en adelante una investigación con finalidad explicativa, previamente habría que llevar a cabo observaciones del statu quo.

Los métodos no-experimentales comprenden esencialmente tres tipos de estudio: a) Estudios de caso; b) Estudios de encuesta; y c) Estudios de campo. La investigación cualitativa es incluida dentro de 105 estudios de campo que realizaran originariamente 105 antropólogos desde fines del siglo XIX (Kerlinger y Lee, 2002: 531-536)6. Pionera de esta clase de trabajos es la estadounidense Margaret Mead (19011978).

Grosso modo, los estudios de campo proceden acopiando datos vía observación participante: el investigador se integra al grupo de estudio convirtiéndose, en lo posible, en miembro activo de éste durante un lapso previsto. En verdad, el estudio de campo se puede plantear de manera dual: el observador puede observar la cultura incorporándose a ésta, o adoptar una actitud objetiva o de observador externo. 
Se reconocen cinco procedimientos de investigación cualitativa: a) Etnografía; b) Etnometodología; c) Investigación-Acción (Rodríguez Gómez et aL, 1996, cap.11) ${ }^{9}$; d) Historias de vida; y e) Grupos de discusión (Mejía, 2002, cap. V) ${ }^{10}$.

La metodología cuantitativa proviene de la tradición neopositivista. No debiera decirse positivista, pues se pasa por alto que, dentro de un nombre común que abrevia a filosofía positiva, del francés Auguste Comte (1798-1857), se incluyen tesis epistémicas afines, pero históricamente distantes y distintas. El positivismo es una actitud normativa que prescribe qué debe entenderse como ciencia (Kolakowski, 1981: 15) ${ }^{11}$.

Para que un conocimiento sea considerado como ciencia debe satisfacer cuatro normas: a) fenomenalismo; b) nominalismo; c) negación de objetividad a 105 juicios de valor; y d) confianza en la unidad fundamental del método de la ciencia. La primera, fenomenalismo, prescribe que lo que aparece en la observación, el fenómeno, es único y es todo lo que hay; no existe lo transempírico. El fenomenalismo estaría en Comte, pero no las tres restantes, que definen al neopositivismo o positivismo lógico o empirismo lógico. (Esas tres normas son lo suficientemente claras como para detenernos en ellas).

El positivista lógico alemán Rudolf Carnap (1891-1970) distinguía dos enfoques históricos en la evolución de la psicología: a) el estudio de eventos introspectivos observables e inobservables; y b) el «conductismo molar». En su perspectiva (Carnap, 1986: 109-110) ${ }^{12}$ : Estos dos enfoques en psicología probablemente convergerán más adelante hacia teorías del sistema nervioso central formuladas en términos fisiológicos. En esta etapa fisiológica de la psicología, que ya ha comenzado, se dará un papel más y más importante a 105 conceptos cuantitativos y a las leyes que se refieren a microestados descritos en términos de células, moléculas, átomos, campos, etc. Y finalmente, la micropsicología podría basarse en la microfísica ... Mi impresión personal ... es que todo el desarrollo de la psicología ... hasta la fundamentación final en microfísica parece hoy mucho más probable y mucho menos remota en el tiempo de lo que parecía incluso hace treinta años.

A su vez, la metodología cualitativa se apoya sobre una concepción del papel del sujeto cognoscente en la búsqueda y obtención de datos. Mejía Navarrete $(2002: 13-31)^{10}$ trata a este respecto una investigación y una sociología de segundo orden, concentrándose en el alemán Niklas Luhmann (1927-1998), el francés Pierre Bourdieu (1930-2002) y el inglés Anthony Giddens (1938- ) como teóricos de la reflexividad.

El concepto de reflexividad, dice Mejía Navarrete (2002: 14) ${ }^{10}$, fue reemplazado por Alfred Schutz (1899-1959) por el de intersubjetividad en papers publicados entre 1940 y el año de su muerte. Para Schutz, el mundo cultural en que vivimos es un mundo intersubjetivo «porque vivimos en él como hombres entre otros hombres, con quienes nos vinculan influencias y labores comunes, comprendiendo a 105 demás y siendo comprendido por ellos» (Schutz, 1995: 41) $)^{13}$.

Pero este reconocimiento no sería una novedad. Desde 1934, polemizando con los positivistas lógicos, el filósofo austriaco Karl R. Popper (1902-1994), subrayaba que «la objetividad de los enunciados descansa en el hecho de que pueden contrastarse intersubjetivamente» (Popper, 1934/1977: 43) ${ }^{14}$.

La investigación de segundo orden que examina Mejía es la segunda cibernética del ingeniero alemán Heinz von Foerster (1911-2002). La primera cibernética, la de Norbert 
Wiener (1894-1964), investiga los medios por los cuales la información se transforma en la actuación deseada en organismos vivos, máquinas y organizaciones. Por ello se dice que la cibernética estudia sistemas de comunicación y de control.

La cibernética de segundo orden se centra en el rol del observador que construye la realidad investigada (Feixas y Vi llegas, 1993: 45) 15. En tal sentido, el investigador participa en la situación que estudia, está situado en el centro de ella. Toda descripción resulta así reflexiva, intersubjetiva o auto-referencial (Feixas y Vi llegas, 1993: 46)15.

Los datos cualitativos serían por lo tanto una alternativa a los datos cuantitativos. Una distinción desapercibida entre investigación cuantitativa e investigación cualitativa sería la que formula Schunk (1997: 6) ${ }^{16}$ : lo que representa a esta última es la calidad del análisis y de la interpretación de los datos. La diferencia entre investigación cuantitativa e investigación cualitativa residiría, pues, en el lenguaje metodológico. No todo aspecto del comportamiento social es susceptible de cuantificación, pero eso no significa que en la realidad haya «fenómenos cuantitativos» $\mathrm{y}$ «fenómenos cualitativos».

Como otras oposiciones postuladas suelen tomar un cariz ideológico, estaríamos ante un seudoproblema, pues no son lo mismo ciencia e ideología. Veamos por qué.

\subsubsection{Una distinción conceptual entre ciencia e ideología:}

El antropólogo Stefano Varese llamó «marxismo simplificador y vulgar» a aquel que obviaba «factores culturales diferenciados relegándolos a la sencilla fórmula cultura es igual a ideología» (Varese, 1971: 48) ${ }^{17}$. En tal sentido, si uno de los elementos de la cultura es la ciencia, ésta caería dentro de esa fórmula. Moraleja: ciencia = ideología.

Pero igualarlas sería confundir orientaciones cuyos orígenes y fundamentos son totalmente diferentes. Epistemología es el estudio crítico de los fundamentos filosóficos, lógicos e históricos de la ciencia y la tecnología como campos de conocimiento. Luego, la cuestión medular es determinar sobre qué se sustentan el conocimiento científico y la ideología, qué los diferencia como formas de representación de la realidad.

Cuando hablamos de ciencia nos referimos a conocimiento fundamentado sobre observaciones y estudios realizados siguiendo métodos y a conclusiones inferidas de pruebas estadísticas. En fin, a experiencias replicables. La ciencia es objetiva, pues está al alcance del público gracias a la difusión y discusión de resultados de investigaciones a nivel planetario.

A su vez, según Mannheim (1993: 53) ${ }^{18}$, ideología es un concepto moderno. Sus raíces estarían en Napoleón I Bonaparte (1769-1821), que llamó «ideólogos» a un grupo de filósofos opuestos a él. El comportamiento de éstos era ideológico en el sentido de estar «apartado de la práctica» (Mannheim, 1993: 64) ${ }^{18}$.

Para Eagleton (1997: 69) ${ }^{19}$, el «último Engels» asocia la noción de ideología con «ideas contaminadas en su raíz». En efecto, en carta dirigida a Franz Mehring, Engels (s. f.: 726727) ${ }^{20}$ le decía a aquél que:

La ideología es un proceso que se opera por el llamado pensador conscientemente, en efecto, pero con una conciencia falsa. Las verdaderas fuerzas propulsoras que lo mueven permanecen ignoradas para él; de otro modo, no sería tal proceso ideológico. Se imagina, pues, fuerzas propulsoras falsas o aparentes. Como se trata de un proceso discursivo, deduce su contenido y su forma del pensar puro, sea el suyo propio o el de sus predecesores. Trabaja exclusivamente con material discursivo, que acepta sin mirarlo, como creación del pensamiento, sin someterlo a otro proceso de investigación, sin buscar otra fuente más alejada e independiente del pensamiento; para él, esto es la evidencia 
misma, puesto que para él todos los actos, en cuanto les sirva de mediador el pensamiento, tienen también en éste su fundamento último. Independientemente del explícito juicio valorativo de falsedad, para Engels, la ideología es uno de los modos como opera el pensamiento. Hay, así, dos mecanismos:

a. la fuerza «propulsara»; y b. el papel del pensamiento como «fundamento último» de la ideología. Así, como dice Villoro, la ideología no es compatible con el pensar discursivo y crítico, pues desempeña una función directriz del comportamiento (Villoro, 1997: 184)21.

Esto expl icaría el hecho de que las ideologías se acepten sin razones que las justifiquen y sin admitir la crítica. «Ideología» devino así en una reificación sui generis: como dice Eagleton (1997: 243) ${ }^{19}$, se aplica al punto de vista que se busca proscribir. La ideología no dispone ni a la investigación ni a la crítica de ésta. Se funda, como dice el propio Engels, sobre el pensar puro. La ecuación: ciencia = ideología, sería corolario de la incomprensión de la estructura y dinámica del conocimiento científico.

Es decir, los fundamentos epistemológicos de la ciencia y la ideología no son los mismos. La ciencia se basa sobre la investigación y la discusión crítica de resultados. En contraste, la ideología se basa sobre creencias y es acrítica. Veamos la segunda parte.

\section{Modelos teóricos, metodológicos y técnicos en psicología como paradigmas}

Estudiando la historia de la ciencia, Thomas S. Kuhn (1922-1996) denominó paradigma a «... realizaciones científicas universalmente reconocidas que, durante cierto tiempo, proporcionan modelos de problemas y de soluciones a una comunidad científica» (Kuhn, 1978: 13) ${ }^{22}$. De allí que todo descubrimiento sería una anomalía que mostraría que "La naturaleza ha violado las expectativas inducidas por el paradigma..."(Kuhn, 1978: 93) ${ }^{22}$. Brevemente, anomalías son contraejemplos, esto es, casos incompatibles con las predicciones del esquema teórico- explicativo del paradigma vigente. Éste los soslaya poniendo en evidencia su insuficiencia teórica. Paulatinamente, esto presionará por un cambio de paradigma, por una revolución científica. Esto parte de una redefinición de la ciencia en la que se produzca aquella revolución. Problemas del paradigma anterior se confinan a otra ciencia o pasan a ser considerados como «no-científicos». Dificultades vistas como fútiles o accidentales, en el nuevo paradigma son arquetipos de realización científica.

Al cambiar los problemas, varían las normas que deciden una solución científica real de una mera especulación: «La tradición científica ... que surge de una revolución ... es no sólo incompatible sino también a menudo realmente incomparable con la que existía con anterioridad» (Kuhn, 1978: 166)22. A esta imposibilidad de comparación entre tradiciones, Kuhn dio el discutido nombre de inconmensurabilidad: el paradigma desplazado y el paradigma reemplazante serían inconmensurables en el sentido de que no habría un lenguaje común entre ellos.

En psicología no hubo revoluciones. La convergencia de modelos (psicoanálisis, conductismo y cognitivismo) sustenta esta aserción. Como lo dice Rorty (1983: 61)23: «nadie puede triunfar empleando argumentos que utilicen inequívocamente términos compartidos con la sabiduría tradicional".

No obstante, la propuesta conceptual presentada en la primera parte consolida la revisión conceptual realizada por Kuhn. Para éste, una comunidad científica es formada por profesionales que pertenecen a un área particular de investigación e intervención. Estos profesionales son copartícipes en la formación académica y en el entrenamiento profesional. Difunden los resultados de sus estudios en conferencias nacionales o internacionales y son solidarios en la formación de generaciones en el aprendizaje y 
práctica de la carrera (Kuhn, 1996: 319) ${ }^{24}$.

En síntesis, los profesionales de la comunidad científica compartirían una matriz disciplinaria. Matriz es entidad generadora: produce investigación. Es disciplinaria por la posesión común de una tradición de conocimientos y acción. En psicología, sólo hay cuatro enfoques teóricoexplicativos y metodológicos con aplicaciones técnicas:

1. El paradigma psicobiológico;

2. El paradigma psicoanalítico;

3. El paradigma conductual; y

4. El paradigma fenomenológico.

Empecemos con el primero.

\subsection{El paradigma psicobiológico:}

El paradigma psicobiológico explica la conducta como resultado de procesos a nivel de los mecanismos y dinámica cerebrales. Los principios de este paradigma son los de la neurociencia en general y de la neurofisiología, en particular. La neurociencia se funda en la doctrina de la neurona, enunciada a fines del XIX por el neurohistólogo español de Santiago Ramón y Cajal (1852-1934), que compartió el Nobel de Fisiología y Medicina en 1906 con el neurocitólogo italiano Camillo Golgi (1844-1926).

La doctrina de la neurona sostiene que la célula nerviosa es la unidad estructural y funcional del sistema nervioso. Cajal logró corroborar la individualidad histológica y funcional de la neurona, el curso del impulso por la neurona y la intercomunicación neuronal. Esta última se da por contigüidad, no por continuidad. Así, Cajal descubrió la sinapsis como forma de conexión interneuronal por contigüidad. Siete son los principios que regulan los procesos físico-químicos de recepción y transmisión de información (Eccles, 1975: 100-101) $)^{25}$ :

1. El principio de transmisión interneuronal de propagación de impulsos;

2. El principio de divergencia en la proyección de una neurona hacia otras;

3. El principio de convergencia en la proyección de varias neuronas hacia una;

4. Cambio de fase eléctrica a fase química y viceversa en la sinapsis;

5. El principio de descarga de fondo de las neuronas cerebrales.

6. El principio de inhibición, que asciende, afina señales y controla descargas neuronales por circuitos de feedback y feedforward; y

7. El principio de la actividad neuronal como base de la función cerebral y de la respectiva mensurabilidad con señales que, en el trabajo sináptico, estimulan neuronas en tipos de organización complejos.

La metodología es correlacional: debe buscarse información sobre covariaciones entre la estructura y la dinámica cerebral y la conducta. A ello sirven los métodos de neuroimagen: tomografía por emisión de positrones y resonancia magnética funcional, que exponen imágenes de la estructura y función cerebrales in vivo durante actividades cognitivas (ver más en Pinel, 2001: 123-127)26.

Las aplicaciones del paradigma psicobiológico se limitan a la neuropsiquiatría, cuyo eje es la psicofarmacoterapia. Pasemos al paradigma psicoanalítico. 


\subsection{El paradigma psicoanalítico:}

La revisión del psicoanálisis se centra en Sigmund Freud (1856-1939). Se omite sus variantes; no por ortodoxia, sino por lo dicho por Freud: "El psicoanálisis es ... obra mía ... Todavía hoy, no siendo ya el único psicoanalista, me creo con derecho a sostener que nadie puede saber mejor que yo lo que es el psicoanálisis ... y qué es lo que puede acogerse bajo su nombre o debe ser excluido de él» (Freud, 1972: 1895) ${ }^{27}$. Freud no tuvo posición precisa en el problema cerebro-mente. Como se sabe, él postuló un mecanismo hipotéticodescriptivo de lo mental. Redactó un esbozo en 1895, sin titularlo, aunque aludiéndolo como su "Psicología para neurólogos». Lo abandonó. El cogollo freudiano lo llama el Entwurf, el Proyecto. Se publicó en inglés en 1950 como Proyecto para una psicología. científica. Para Rof Carballo (1972: 21$)^{28}$ :

"Freud, para consagrarse a su obra, reprime, rechaza toda su larga labor. .. de neurólogo». Pero su definición de Trieb, impulso instintivo, deja entrever una visión dualista. Es una idea central en el psicoanálisis, por lo que cabe examinarla. Hay un ensayo de Freud de 1915 que salió publicado en inglés como: "Instincts and their vicissitudes». En español sería: "Metapsicología de los instintos, la represión y el inconsciente». Como se ve, en vez de Trieb, aparece instinct, «instinto». No se podría decidir si Freud escribió Trieb o Instinkt: Wallwork (1994: 174)29 advierte que Freud raras veces usó esta última palabra; y, cuando, lo hizo, se refería a las pautas preestablecidas de comportamiento de las que hablan los etólogos.

En relación con esto, Rof Carballo anota diversas dificultades con los términos del psicoanálisis: "La palabra "Trieb» que en inglés es traducida por «drive», no tiene en castellano un correcto correlato. Es impulso y tensión, empuje y «resorte instintivo». Algo que se distiende y que fuerza a esa distensión» (Rof Carballo, 1972: 96)28. No está de más oír a Freud (1974: 94)30 sobre el Trieb:

y si ahora procedemos a considerar la vida mental desde un punto de vista biológico, el «instinto» nos parece ser un concepto de región limítrofe entre lo mental y lo físico, siendo a la vez el representante mental de los estlmulos que proceden de dentro del organismo y llegan a la mente y, al propio tiempo, una medida de la demanda puesta a la energía de esta última como consecuencia de su conexión con el cuerpo. Para Assoun (1982: 69)31, esta actitud de Freud es agnóstica. Aduce que fue precedido en ello por el fisiólogo francés Émile Du Bois-Reymond (1818-1896), conocido, entre otras cosas, por su agnosticismo. Assoun usaría este término metafóricamente, que, en rigor, nombra a la actitud que asume que la existencia de Dios ni es segura ni imposible. El término viene de una voz griega que significa «no conocido».

Para Du Bois-Reymond, jamás podríamos acceder al conocimiento de cómo la función cerebral produce lo mental (su lema era: ignoramus et ignorabimus, «ignoramos e ignoraremos»). La definición de Trieb de Freud, sin embargo, no lo haría agnóstico. Él llamó metapsicología a su obra. Expuso, entre otros, tres puntos explicativos:

1. Un punto de vista topográfico, según el cual la conducta es expresión de un aparato psíquico integrado por una «proyección mental» de la superficie del cuerpo, el yo (Freud, 1974: 2709) ${ }^{32}$; por la profundidad de éste, el Ello, ignoto e inconsciente (Freud, 1974: 2707) ${ }^{32}$; y por el <<ideal,) del yo, el súper-yo (Freud, 1974: 2710) ${ }^{32}$;

2. Un punto de vista dinámico, representado en la tesis de que la conducta está funcionalmente determinada por impulsos básicos como el impulso de vida y el impulso de destrucción o muerte (Freud, 1974: 2716-2721) ${ }^{33}$; y

3. Un punto de vista económico según el cual toda conducta consume energía y es regulada 
por ésta mediante unidades de energía psicológica, las catexias (Rapaport, 1967: 60$64)^{34}$.

Según Freud (1974: 2775-2776) ${ }^{33}$ : «La articulación de lo inconsciente se halla enlazada con la tentativa de representamos el aparato anímico compuesto por una serie de instancias... de cuya relación entre sí hablamos desde un punto de vista espacial, independiente en absoluto de la anatomía real del cerebro. Es éste el punto de vista... tópico». He aquí el dualismo freudiano. Dos principios fundamentales explican la conducta: a) el principio del placer, principio hedonístico según el cual el comportamiento está dirigido a la búsqueda de satisfacción y la disminución o supresión de displacer; y b) el principio de realidad, que asienta que el contexto regula la satisfacción de impulsos básicos.

La metodología psicoanalítica es inductivista e intuicionista. En la metodología inductivista se asume que el conocimiento se basa sobre la observación. A partir de ésta se infieren las generalizaciones. Inductivismo supone verificacionismo. Éste consiste en la tendencia a preferir la búsqueda de confirmaciones de las hipótesis formuladas, antes que la evaluación crítica de ellas. Freud manifestó esta tendencia. Es conocida su actitud ante las críticas formuladas en un principio al psicoanálisis (Freud, 1955: 108) ${ }^{35}$ :

Las fuertes resistencias contra el psicoanálisis no eran de índole intelectual, sino que procedían de fuentes afectivas: esto permitía explicar su apasionamiento y su falta de lógica. La situación se adaptaba a una fórmula muy simple: los hombres, en tanto que masa humana, se conducían frente al psicoanálisis exactamente igual que un individuo neurótico sometido a tratamiento por sus trastornos, pero al cual se podía demostrar pacientemente que todo había sucedido como el psicoanálisis lo afirmaba. Por otra parte, tales hechos no fueron inventados por esta ciencia, sino hallados en el estudio de otros neuróticos, mediante esfuerzos prolongados durante varios decenios.

Semejante situación tenía, al mismo tiempo, algo terrible y algo grato: terrible, porque no era ninguna minucia tomar a la especie humana como paciente; grato, porque a fin de cuentas todo venía a suceder como, de acuerdo con las hipótesis del psicoanálisis, debía ocurrir.

El fragmento es elocuente. Además, podría añadirse la apelación a la autoridad, lo que es deducible de este juicio: «... el análisis no se presta a usos polémicas. Presupone una aquiescencia total del analizado y la existencia de un superior y un subordinado» (Freud, 1972: 1920$)^{27}$.

Esto apuntaría al modus operandi de la técnica. Él decía que su teoría: «Tolera tan bien como la física o la química que sus conceptos superiores sean oscuros y sus hipótesis provisionales, y espera de una futura labor una más precisa determinación de los mismos» (Freud, 1953: 201) ${ }^{36}$.

No obstante, las suyas no serían hipótesis tan «provisionales». Él mismo escribió que la «hipótesis de la existencia de procesos psíquicos inconscientes, el reconocimiento de la teoría de la resistencia y de la represión, la valorización de la sexualidad y el complejo de Edipo son los contenidos capitales» del psicoanálisis y «los fundamentos de su teoría». Pero esto se contradice con lo que señalaba páginas antes: «quien no los acepta todos, no debía contarse entre los analíticos» (Freud, 1953: 194-195) ${ }^{38}$.

El intuicionismo psicoanalítico radica en el aprecio de Freud a la comprensión empática como medio de conocimiento. El intuicionismo defiende a la intuición como medio de conocimiento. Intuición es aprehensión directa de las cosas. Es distinta y, para algunos, incluso superior al conocimiento racional: en este último, el conocimiento es mediado por 
la argumentación; en la intuición, el conocimiento es directo, por captación intelectual o emotiva.

Freud elogió la comprensión implícita en la empatía. Para él, en la comprensión «nos hallamos ante el proceso denominado... Einfuehlung ..., proceso del que depende en su mayor parte nuestra comprensión del yo de otras personas» (Freud, 1987: 45) ${ }^{37}$. Einfühlung es, en efecto, empatía, es la identificación mental y afectiva que una persona descubre entre ella y las vivencias de otra persona; es «un reencontrarse del yo en el tú» (Dilthey, 1978: $215)^{38}$. Para terminar, veamos los aspectos técnicos.

Las aplicaciones técnicas del psicoanálisis son las mismas que introdujera Freud. Serían cinco: a) asociaciones libres normadas por la regla fundamental del psicoanálisis: en estado de distensión e incoerciblemente el pensamiento libera ideas reprimidas; b) interpretación de los sueños, mediante análisis del contenido manifiesto para descifrar el contenido latente o enmascarado; c) análisis de actos fallidos (errores, olvidos o ironías) representativos de la «psicopatología de la vida cotidiana; d) análisis de resistencias, en que se evalúa los medios de evasión de obligaciones (somatización e intelectualización); y e) análisis de la transferencia, relación sujeto-analista donde el primero reproduce las reacciones tenidas con personajes importantes de su vida familiar, educacional y laboral (la relación inversa es la contratransferencia).

En la siguiente sección se revisará el paradigma conductual.

\subsection{El paradigma conductual:}

El paradigma conductual es modelo de aprendizaje (Bernstein y Nietzel, 1982, cap. 10) ${ }^{39}$. Por tanto, para la teoría respectiva, las relaciones entre entorno y conducta determinan los cambios en ésta. Tres principios fundamentan el paradigma conductual:

1. El principio de adquisición por condicionamiento clásico;

2. El principio de adquisición por condicionamiento operante; y

3. El principio de adquisición por aprendizaje imitativo.

El condicionamiento clásico es un principio de adquisición conductual que tiene lugar si un estímulo que no produce una respuesta comienza a hacerlo después de que se le hace seguir inmediata y sistemáticamente por el estímulo que sí la produce. Se trata de un nuevo patrón de respuesta, pues la conducta que en un inicio se dio sólo ante una forma de estímulo se traslada hacia otra. La adquisición por condicionamiento clásico es producto de relaciones entre sucesos (Rachlin, 1979: 241) ${ }^{40}$. Es «clásico» por que el esquema experimental primigenio fue Introducido por Pavlov.

El condicionamiento operante es un principio que afirma que el comportamiento se adquiere, desarrolla y mantiene por las consecuencias que produce en el contexto. Es condicionamiento «operante» porque en él el comportamiento «opera» sobre el entorno. Los efectos que produce con estos se llaman reforzadores. El aprendizaje por condicionamiento operante es resultado de relaciones entre conducta y consecuencias (Rachlin, Ibíd.) ${ }^{40}$. El condicionamiento operante fue descubierto por B. F. Skinner.

El aprendizaje imitativo es el principio de adquisición conductual de la teoría del aprendizaje social de Albert Bandura (1925). Es una teoría social-cognitivista (Bower y $\mathrm{H} \mathrm{i}$ Igard, 1989: 571-579) ${ }^{41}$. Es social porque, para Bandura, aunque «cierta cantidad de aprendizaje tiene lugar mediante el entrenamiento y la recompensa directa, buena parte del 
repertorio de conductas de una persona puede ser adquirido a través de la imitación de lo que observa en otro» (Bandura, 1979: 215) ${ }^{42}$.

y es cognitivista, pues para Bandura aprendizaje es «actividad de procesamiento de información en la que los datos acerca de la estructura de la conducta y de los acontecimientos del entorno se transforman en representaciones simbólicas que sirven como lineamientos para la acción» (citado según Schunk, 1997: 109) ${ }^{16}$. El paradigma no es conductual, sino «conductista».

Se distingue entre conductismo radical y conductismo metodológico. Skinner es radical. Lo identifica su tesis de que un análisis de cómo los sucesos del entorno afectan a la conducta basta para explicarla (Skinner, 1971: 60) ${ }^{43}$. Es radical al eliminar de raíz a la mente. A este último respecto él es claro.

Para Skinner, no debe decirse que la conducta se emite», sino aparece. Emisión da la impresión de que la respuesta está en el organismo y luego se exterioriza. Él formula una analogía que resume hábilmente su abstracción de la interioridad: " la palabra «emisión» no necesariamente debe indicar «sacar; en el filamento caliente no hay luz antes de que se emita» (Skinner, 1975: 56) ${ }^{44}$

El conductismo radical, el método y la tecnología que lo respaldan (análisis experimental de la conducta y análisis conductual aplicado, respectivamente) son fruto de la posición e investigaciones de Skinner.

El conductismo metodológico es metodológico porque acepta que la observación de la conducta es el método fundamental de la psicología, sin dejar por ello el estudio de procesos mentales. Las vigas maestras del conductismo metodológico vienen de Edward Tolman. Éste introdujo entre 1935-1938 el lenguaje metodológico que usamos (Leahey, 1998: 397-398) $)^{45}$. Formuló un modelo teórico con tres variables: a) independientes; b) intervinientes; y c) dependientes.

Variables independientes son las condiciones de experimentación o del entorno cuyos efectos influyen primeramente sobre el estado fisiológico o psicológico que en un momento dado se atraviesa. Variables intervinientes son dichos estados. Finalmente, las variables dependientes son las medidas de conducta resultantes de la influencia de las variables independientes sobre las variables intervinientes. Esta atención de los procesos fisiológicos y psicológicos caracterizó al conductismo metodológico como base teórica de dos aplicaciones técnicas del paradigma conductual, la terapia conductual y la terapia racionalemotiva. En conjunto, las aplicaciones técnicas del paradigma conductual son las técnicas de modificación de conducta, una familia de técnicas que constaría de cuatro grupos: a) terapia conductual; b) análisis conductual aplicado; c) terapia conductual-cognitiva; y d) entrenamiento en autocontrol. La terapia conductual combina condicionamiento clásico, operante y aprendizaje imitativo.' Sus técnicas características son la desensibilización sistemática (OS), el entrenamiento en habilidades sociales (EHS), el condicionamiento encubierto y la biorretroalimentación o biofeedback.

La DS conjuga entrenamiento en relajación muscular progresiva y evocaciones de situaciones generadoras de tensión para el tratamiento de problemas emocionales relacionados con ansiedad neurótica. Se basa sobre el contracondicionamiento: principio de sustitución que reemplaza la respuesta-problema por respuestas incompatibles con ella. La OS sustituye ansiedad por relajación (Rimm y Masters, 1980: $61{ }^{46}$. 
El EHS entrena en conducta asertiva. Ésta es conducta que expresa rectamente sentimientos aprobatorios o discrepantes, estos últimos sin lesionar la auloestima ajena. También se basa sobre contracondicionamiento; se aplica a la terapia de ansiedad social, problemas de pareja y estrés laboral. El EHS sustituye ansiedad social por la relajación representada en la asertividad. Su práctica incluye una exposición de conductas modelo, ensayo conductual, juego de roles y ejecución de comportamiento asertivo (Olivares y Méndez, 2001, cap. IX) $)^{47}$.

El condicionamiento encubierto aplica el condicionamiento operante para tratar las respuestas encubiertas (sentimientos, emociones, creencias o deseos) que preceden y propician conductas-problema. El biofeedback o retroalimentación biológica comprende un grupo de técnicas de condicionamiento operante con equipos de control y monitoreo de respuestas viscerales y musculares implicadas en desórdenes psicosomáticos.

Por su parte, el análisis conductual aplicado «aplica» el análisis experimental del comportamiento a la solución de problemas en psicología profesional. Este análisis es manejo de contingencias. Contingencia es relación de consecuencia o condicionalidad entre conducta y consecuencias en el entorno. La relación es de la forma: $\mathrm{R}-\mathrm{E}$, donde $\mathrm{R}$ es la respuesta y es condición para que ocurra E. Ésta es contingencia de refuerzo. Las contingencias de refuerzo forman una triple relación: a) la situación en que ocurre una conducta; b) la conducta misma; y c) las consecuencias de la conducta.

Las técnicas básicas del análisis conductual aplicado son dos: a) técnicas para adquisición, desarrollo y mantenimiento de conductas; y b) técnicas para reducción y eliminación de conductas. Éstas se basan en principios del condicionamiento operante: reforzamiento, extinción y castigo. Las primeras emplean reforzamiento positivo y sus variaciones. El reforzamiento positiva procede presentando un estímulo contingente o seguidamente a la aparición o ejecución de una respuesta.

Técnicas de reducción y eliminación de conductas son dos: a) extinción; y b) castigo (ver más en Olivares y Méndez, 2001: 159-176) ${ }^{47}$. Extinción es supresión de reforzamiento. El castigo opera en dos formas: castigo positivo y castigo negativo. El castigo positivo es presentación de un estímulo punitivo seguidamente a la respuesta que se desea eliminar. Castigo negativo es eliminación contingente de un reforzamiento ante una conductaproblema. También se llama «costo de respuesta». Así, el principio rector del análisis conductual aplicado es el conductismo radical de Skinner. Esto es, su tesis de que «un análisis de cómo los sucesos del entorno afectan a la conducta basta para explicarla» conduce a la prescindencia absoluta de las variables «intervinientes».

A su vez, la terapia conductual-cognitiva es conductista metodológica. Las más definidas son: a) la terapia cognitiva de Aaron Beck; y b) la terapia racional-emotiva de Albert Ellis. Hay otras (ver Olivares y Méndez, 2001: 411-412)47, pero éstas bastarían para un análisis multiparadigmático. La terapia conductual-cognitiva se apoya en tres premisas (Olivares y Méndez, 2001: 411) ${ }^{47}$ :

1. La atención selectiva y la codificación simbólica son los procesos cognitivos con los que las personas desarrollan patrones de comportamiento apropiados o no para el ajuste al entorno social;

2. Dichos procesos pueden ser activados funcional mente por procedimientos isomorfos a los del aprendizaje humano en el laboratorio; y 
3. La labor del terapeuta es diagnosticar y educar en dos fases. Debe: a) evaluar procesos cognitivos desajustados; y b) organizar experiencias de aprendizaje que reestructuren cogniciones y modifiquen pautas afectivas y conductuales.

Según el principio medular de la terapia de Beck (1921- ), emociones y conducta están determinadas por el modo en que se construye el mundo percibido, sea éste el mundo circundante o el mundo que cada quien es en sí mismo. Esto es semejante a la concepción del paradigma fenomenológico, como se verá luego.

A su turno, la terapia racional-emotiva de Albert Ellis (1913- ) también procede de acuerdo con la tesis de que los problemas psicológicos son consecuencia de patrones de pensamiento irracionales. El modelo asume que el comportamiento está determinado por una relación entre acontecimientos de la forma A-B-C-D-E (Rimm y Masters, 1980: 453) ${ }^{46}$. «A» es un suceso que se afronta en una ocasión; «8» (de belief, creencia) es la cadena de pensamientos (autoverbalizaciones) en respuesta $\mathrm{a} \ll \mathrm{A} »$. Consecuentemente, $\langle\mathrm{C} »$ designa $\mathrm{a}$ las emociones y conductas desencadenadas por «8». «D» nombra a los esfuerzos del terapeuta para modificar lo que acontece en «8»; y «E» es resultado de «D»: es la reestructuración cognitiva y emocional resultante de la terapia. Para terminar, veamos las líneas generales del entrenamiento en autocontrol.

El entrenamiento en autocontrol es un grupo de estrategias orientadas a adiestrar al sujeto de tratamiento en auto-administración de contingencias de reforzamiento. Ésta es una meta realizable solamente después de que la técnica de modificación de conducta empleada haya evidenciado los progresos esperados. Ello quiere decir que el consultante ya estaría en aptitud de abandonar la relación terapeuta-cliente (Thoresen y Mahoney, 1981: 22-23) ${ }^{48}$.

Las técnicas de autocontrol se basan sobre el condicionamiento operante. En tal sentido, la persona misma pone en práctica consigo los principios de este último a través de seis técnicas (Thoresen y Mahoney, 1981, caps. III-VI) ${ }^{48}$ : a) auto-observación y auto-registro; b) control de estímulos; c) auto-refuerzo; d) auto-castigo; e) entrenamiento en autoinstrucción; y e) autocontrol de respuestas encubiertas.

Veamos el paradigma final.

\section{4 El paradigma fenomenológico:}

Fenomenología viene del griego paıvó fenomenológico procede pon iendo entre paréntesis, suspendiendo todo prejuicio o juicio, cualquier noción preconcebida o proveniente del conocimiento científico, para centrar la atención en lo que se da o aparece en la conciencia, en la observación. Este método ha sido aplicado en psicología desde los últimos veinte años. Para R. Lazarus, su teoría de las emociones es fenomenológica: «Dado que la evaluación cognitiva se apoya en la interpretación subjetiva de un acontecimiento, podemos decir que es fenomenológica» (Lazarus y Folkman, 1986: 70) ${ }^{49}$. En esta perspectiva (Lazarus y Lazarus, 2000: $21^{50}$ :

No importa cómo intentamos tranquilizar a las personas diciéndoles que no existe motivo para que se sientan enojadas, ansiosas, culpables, avergonzadas, tristes, envidiosas o celosas. este intento no servirá de mucha ayuda ... Lo que puede resultar más eficaz si queremos brindar ayuda y apoyo es comprender los significados personales que estos individuos otorgan a los acontecimientos, que a su vez suscitan las emociones que sienten. También se incluye a la fenomenología entre los enfoques de investigación cualitativa Morse, 2003) ${ }^{51}$. González Rey disiente de esto. 
Para él, «la filosofía no representa en ningún caso un conjunto de referentes estáticos que están listos para ser aplicados como fórmulas en un campo del conocimiento» (Gonzáles Rey, 2003: 43) ${ }^{52}$. Por ello, «la cuestión de la esencia de la conciencia, en. la fenomenología, que está estrechamente asociada con la reducción fenomenológica ..., no puede ser convertida en principio a priori de la investigación psicológica, dado que ella misma está en el centro de los problemas a investigar. .. » (Gonzáles Rey, 2003: 43.44) ${ }^{52}$.

Edmund Husserl (1859-1938), filósofo introductor del método fenomenológico, anticipó que estriba «en abstenemos por completo de juzgar acerca de las doctrinas de toda filosofía anterior y en llevar a cabo todas nuestras descripciones dentro del marco de esta abstención» (Husserl, J995: 46-47; cursivas de él) ${ }^{53}$. Además, el concepto de la esencia de la conciencia no es un principio a priori, sino es tránsito de lo empírico a lo conceptual. Franquear la observación del comportamiento de un sujeto para definir su estructura de personalidad es delimitar su esencia. (Esencia es «estructura»: designa al conjunto de atributos que identifican a un sujeto de tal modo, que sin ellos dejaría de ser lo que es, quedaría des-estructurado).

Esto ratificaría la posibilidad de separar un método de la teoría en la cual surgió. Los criterios de evaluación teórica y metodológica son diferentes: el valor de una teoría lo decide su potencia explicativa y predictiva, mientras que el del método reside en su valor heurística o de búsqueda. Marx (1867/2001, I: XXIV) ${ }^{54}$ se valió así de Hegel:

El hecho de que la dialéctica sufra en manos de Hegel una mistificación, no obsta para que este filósofo fuese el primero que supo exponer de un modo amplio y consciente sus formas generales de movimiento. Lo que ocurre es que la dialéctica aparece en él invertida, puesta de cabeza. No hay más que darle la vuelta, mejor dicho ponerla de pie, y en seguida se descubre bajo la corteza mística la semilla racional.

Al paradigma fenomenológico lo representarían la terapia centrada en el cliente de Carl Rogers y la terapia gestáltica del psiquiatra alemán Friedrich (o Fritz) Perls. Aquí reseño la teoría y metodología de Rogers: la terapia de Perls no resistió suspicacias respecto de su replicabilidad y lenguaje (Bernstein y Nietzel, 1982: 474478) ${ }^{41}$. Incluso no se admite como derivación de la escuela berlinesa de la Gestalt: Wolfgang Kbhler (1887-1967) la desconoció como descendiente genuino de esta escuela (Hothersall, 1997: 253) ${ }^{55}$. Dentro de este paradigma se acostumbró incluir a la psicología existencial. Un exponente prestigioso es Rollo May (19091994), cofundador del movimiento de la psicología humanista. El humanismo invocado es el humanismo ético kantiano, para el cual la dignidad suprema de cada ser humano reside en el hecho de que, desde el cigoto, cada persona es un fin en sí mismo (Kant, 1788/2000: 183) ${ }^{56}$. Según May, en psicología «existencial», este último término designa una actitud hacia la terapia, «no un conjunto de nuevas técnicas» (May, 1974: 175$)^{57}$.

La actitud se revela en el hecho de que «todo psicoterapeuta es existencialista en la medida en que está en condiciones de comprender al paciente en su realidad» ( $M$ ay, Ibíd.)57. Esto lo asimila a la terapia rogeriana, que revisaremos a continuación. 


\subsection{La terapia centrada en el cliente de CarJ R. Rogers:}

Entrevistándolo, R. Evans preguntó a Rogers sobre el curso que había tomado el estudio de la percepción dando más importancia a la experiencia del individuo: «¿Este enfoque fenomenológico (le) interesa ..., más que las reacciones ... a unos estímulos ... ?»:

Sí, desde luego. Pienso que soy un caso representativo de esa tendencia que usted acaba de mencionar. Para mí, el estrecho campo de la percepción es un hecho neurológico que vale la pena estudiar, pero que me interesa relativamente poco. Ya que a mí me interesa más la Cestalt de lo que la persona percibe en su medio y en sí misma. Una cosa que me parece muy cierta es que no hay percepción sin significado. Es decir, que el organismo humano atribuye inmediatamente un significado a lo que percibe (Evans, 1987: 259) ${ }^{58}$.

Rogers es claro: allí admite su filiación fenomenológica. Para él, desde niño, el hombre percibe su experiencia como realidad, le es inmanente la tendencia a la autorrealización y lo dirige esta tendencia (Rogers, 1974: 188-189) ${ }^{59}$. La tendencia a la autorrealización implica una tendencia a la diferenciación. Diferenciación que a su vez redunda en una conciencia de ser. Esta conciencia de ser no es otra cosa que la experiencia del yo.

Consecuentemente, la metodología y la terapia rogerianas se centran en las fases que se deben consumar para la diferenciación, para el proceso de formación del yo. Así, antes que un mero «conjunto de técnicas», la terapia centrada en el cliente es un proceso de relación interpersonal construido por el especialista a efectos de que su «cliente» use dicha relación para el crecimiento personal ulterior (Bernstein y Nietzel, 1982: 444) ${ }^{39}$. Tres actitudes interdependientes norman la terapia: a) estimación positiva incondicional; b) empatía; y c) congruencia.

La estimación positiva incondicional es el pilar de la terapia rogeriana. Contiene tres aspectos: a. preocupación efectiva por el consultante; b. aceptación; y c: convicción en la capacidad de cambio y crecimiento que le es intrínseca al cliente.

La preocupación debe ser efectiva: no son inusuales la preocupación formalista y encimadora. Vale decir, debe ser una preocupación que exprese un cuidado no posesivo de la persona. Esto lo atestigua un explícito deseo de escuchar, manifiesto en atención constante, acuciosidad y calidez ante lo que el cliente dice.

Lo incondicional reside en la decisión del terapeuta de aceptar a su cliente como es, obviando prejuicios. Para Rogers, la experiencia de ser estimado como persona, al margen de la calidad de los sentimientos o costumbres del cliente, puede coadyuvar al crecimiento, en especial, de aquellos cuyo desarrollo es frustrado por presiones de valor socialmente instaladas. Aceptación del cliente significa que el terapeuta debe abstenerse de juicios de valor.

Y el «componente positivo» de la estimación incondicional, de otra parte, estriba en la convicción del terapeuta en la capacidad del cliente para enfrentar problemas y emprender el trabajo de crecimiento personal. Esta convicción no es mera expectación. Es una construcción propiciada por el terapeuta dentro de las salidas que él prevea en el proceso de solución de problemas. Es la anticipación de consecuencias que provendrán de las decisiones que adopte el propio cliente.

La estimación incondicional positiva es el capítulo ético-humanista de la terapia centrada en el cliente, mientras la empatía es el aspecto propiamente fenomenológico. Lo testimonia 
la aseveración de Rogers relacionada con su interés respecto de la Gestalt que la persona percibe de su entorno y de sí misma.

La comprensión empática es la comprensión diltheyana, referida líneas arriba en relación con el intuicionismo psicoanalítico. Para Rogers, requiere de un acercamiento del terapeuta a la interpretación que el cliente tiene del mundo, .de modo que, cuando se haga explícita la comprensión, se haga posible una relación interpersonal fructífera entre el primero y el segundo. La empatía no es emocional, sino cognitiva: no se trata de que el terapeuta sienta lo mismo que el cliente. Esto sería «simpatía», lo que trastocaría todo el proceso. Se trata de que el terapeuta conozca las condiciones que atraviesa su cliente para que descifre o se sitúe en los pensamientos y sentimientos desencadenados.

Por último, congruencia es, lisa y llanamente, coherencia, consistencia. Éste es un requisito que debiera satisfacer la relación entre lo que se piensa, se siente y se dice en esa relación interpersonal que es la terapia centrada en el cliente. La recomendación es de difícil cumplimiento, pero calza con la prédica humanista de sentir lo que se dice y decir lo que se siente. 


\section{CONCLUSIONES}

\section{Programas y fusiones}

Conjuntamente a los paradigmas asoman cada cierto tiempo proyectos psicoterapéuticos o metodológicos que recuerdan a los programas de investigación del filósofo húngaro Imre Lakatos (1922-1974). Para éste, programa de investigación es una sucesión de teorías unificadas por una continuidad histórica que relaciona a los miembros de una comunidad científica en torno a problemas. Consta de reglas que prescriben derroteros a seguir, la heurística positiva, y derroteros a evitar, la heurística negativa (Lakatos, 1983: 65-72) ${ }^{60}$.

En un sentido más lato, sin embargo, el constructivismo y las técnicas sistémicas vendrían de programas que aún no han cuajado como esquemas uniformes en la praxis. La terapia familiar es una terapia, y una terapia prestigiada; no es una trilogía coherente teoríamétodo-técnica. Lo mismo diría de una de sus derivaciones, la terapia de pareja.

Un contra-argumento a este respecto sería que la terapia familiar es sistémica, y, como tal, los presupuestos y la metodología subyacentes están representados en la teoría general de los sistemas del austriacocanadiense Ludwig von Bertalanffy (1901-1972). Una tesis central en esta teoría sostiene la determinación por interdependencia entre los elementos del sistema, por lo que la causalidad lineal (E - R) no tendría cabida en ella.

Como fuere, también hay fusión de perspectivas teóricas y aplicaciones técnicas. Esto se ve en la terapia dialéctica conductual de Linehan, técnica cognitivo-conductual que conjuga terapia individual y entrenamiento en habilidades sociales (Linehan, 2003: 19) ${ }^{61}$. Es dialéctica en sentido hegeliano de la serie tesis-antítesis síntesis, "compatible con los modelos de conflicto psicodinámicos de la psicopatología. El pensamiento, la conducta y las emociones... extremas... son ... fracasos dialécticos» (Linehan, 2003: 21 ) ${ }^{61}$. El diálogo y el intercambio ponen en juego la dialéctica. La metafísica subyacente es el holismo (del griego, holós, todo), ya que concibe la realidad como totalidad. Semejantes fusiones, sin embargo, difícilmente llegarían a formar un paradigma en los términos expuestos, lo cual no es demérito. Por último, insistir en un «paradigma único» en psicología sería una causa perdida. Equivaldría a creer en la posibilidad de un «pensamiento único» en psicología. De ser así, estaríamos ante un nuevo reduccionismo que soslayaría la multideterminación de la conducta humana. 


\section{REFERENCIAS}

1. Clemente, M. y F. Molero (1994). Estudio psicosocial de la delincuencia y participación política no convencional. En J. F. Morales (Coord.), Psicología social, págs. 845-873. Madrid: McGrawHill/Interamericana de España.

2. Fernández, C. (1974). Los filósofos antiguos. Selección de textos. Madrid: Biblioteca de Autores Cristianos.

3. Kant, I. (1781/1979). Crítica de la razón pura. Volumen I. Buenos Aires: Losada.

4. Fernández, C. (1974). Los filósofos medievales. Vol. II. Selección de textos. Madrid: Biblioteca de Autores Cristianos.

5. Leahey, T. y R. Harris. (1998). Aprendizaje y cognición. Madrid: Prentice Hall.

6. Bunge, M. (1980). Epistemología. Barcelona: Ariel.

7. O'Neil, W. M. (1968). Introducción al método en psicología. Buenos Aires: Eudeba.

8. Kerlinger, F. y H. Lee (2002). Investigación del comportamiento. México: McGraw Hill/ Interamericana.

9. Rodríguez G., J. Gil Flores y E. Garda Jiménez (1996). Metodología de la investigación cualitativa. Málaga: Aljibe.

10. Mejía Navarrete, J. (2002). Problemas metodológicos de las ciencias sociales en el Perú. Lima: UNMSM-Fondo Editorial de la Facultad de Ciencias Sociales.

11. Kolakowski, L. (1981). La filosofía positivista. Madrid: Cátedra.

12. Carnap, R. (1986). El carácter metodológico de los conceptos teóricos. En J. Rolleri (Dir.), Estructura y desarrollo de las teorías científicas, págs. 69-111. México: UNAM.

13. Schutz, A. (1995). El problema de la realidad social. Buenos Aires: Amorrortu.

14. Popper, K. R. (1934/1977). La lógica de la investigación científica. Madrid: Tecnos.

15. Feixas, G. y M. Villegas. (1993). Constructivismo y psicoterapia. Barcelona: PPU.

16. Schunk, D. (1997). Teorías del aprendizaje. México: Prentice Hall Hispanoamericana.

17. Varese, S. (1971). Consideraciones de antropología utópica. Textual. Revista de Artes y Letras del Instituto Nacional de Cultura, Lima, Perú, 1, 48-50, junio.

18. Mannheim, K. (1993). Ideología y utopía. México: Fondo de Cultura Económica.

19. Eagleton, T. (1997). Ideología. Barcelona: Paidós Ibérica.

20. Engels, F. (1893/s.f.). Engels a Mehring. En Marx-Engels, Obras escogidas, págs. 726730. Moscú: Progreso.

21. Villoro, L. (1997). El poder y el valor. México: El Colegio Nacional. FCE.

22. Kuhn, T. (1978). La estructura de las revoluciones científicas. México: FCE.

23. Rorty, R. (1995). La filosofía y el espejo de la naturaleza. Madrid: Cátedra.

24. Kuhn, T. (1996). La tensión esencial. México: FCE.

25. Eccles, J. (1975). El cerebro. México: Interamericana.

26. Pinel, J. (2001). Biopsicología. Madrid: Pearson Educación. 
27. Freud, S. (1972). Historia del movimiento psicoanalítico. En Obras Completas. Tomo V, págs. 1895-1930. Madrid: Biblioteca Nueva.

28. Rof Carballo, J. (1972). Biología y psicoanálisis. Bilbao: DDB. 29.Wallwork, E. (1994). El psicoanálisis y la ética. México: FCE.

30. Freud, S. (1974). Metapsicología de los instintos, la represión y el inconsciente. En T. Millon, Psicopatología y personalidad, pp. 92-101. México: Interamericana.

31. Assoun, P. (1982). Introducción a la epistemología freudiana. México: Siglo XXI.

32. Freud, S. (1974). El «yo y el «Ello». En Obras Completas. Tomo VII, págs. 27012728. Madrid: Biblioteca Nueva.

33. Freud, S. (1974). Autobiografía. En Obras Completas Tomo VII, págs. 27612800. Madrid: Biblioteca Nueva.

34. Rapaport, D. (1967). La estructura de la teoría psicoanalítica. Bs. As.: Paidós.

35. Freud, S. (1955). Las resistencias contra el psicoanálisis. Obras Completas. Tomo XIX, págs. 99-109. Buenos Aires: Santiago Rueda.

36. Freud, S. (1953). El psicoanálisis y la teoría de la I ibido. Obras Completas, tomo XVII, págs. 183-204. Buenos Aires: Santiago Rueda.

37. Freud, S. (1987). Psicología de las masas. Madrid: Alianza.

38. Dilthey, W. (1978). El mundo histórico. México: FCE.

39. Bernstein, D. y M. Nietzel (1982). Introducción a la psicología clínica. México: McGraw-Hill.

40. Rachlin, H. (1979). Comportamiento y aprendizaje. Barcelona: Omega. 41.Bower, G. y E. Hilgard (1989). Teorías del aprendizaje. México: Trillas.

42. Bandura, A. (1979). La psicoterapia como un proceso de aprendizaje. En Nudler, O. (comp.), Problemas epistemológicos de la psicología, págs. 202-227. México: Trillas.

43. Skinner, B. F. (1971). Ciencia y conducta humana. Barcelona: Fontanella.

44. Skinner,B. F. (1975). Sobre el conductismo. Barcelona: Fontanella.

45. Leahey, T. (1998). Historia de la psicología. Madrid: Prentice Halllberia.

46. Rimm, D. y J. Masters (1980). Terapia de la conducta. México: Trillas.

47. Olivares, J. y F. Méndez (2001). Técnicas de modificación de conducta. Madrid: Biblioteca Nueva.

48. Thoresen, C. y M. Mahoney (1981). Autocontrol de la conducta. México: FCE.

49. Lazarus, R y S. Folkman (1986). Estrés y procesos cognitivos. Barcelona: Martínez Roca.

50. Lazarus, R. y B. Lazarus (2000). Pasión y razón. Barcelona: Paidós Ibérica.

51. Morse, J. (ed., 2003). Asuntos críticos en los métodos de investigación cualitativa. Colombia: Universidad de Antioquia.

52. González R., F. (2003). La investigación cualitativa en psicología: Algunas cuestiones actuales. En Revista de Psicología, VI, 2, Noviembre, págs. 41-56. Facultad de Psicología-UNMSM. Lima-Perú. 
53. Husserl, E. (1913/1995). Ideas relativas a una fenomenología pura y una filosofía fenomenológica. México: FCE.

54. Marx, K. (1867/2001). El capital. Vol. I. México: Fondo de Cultura Económica.

55. Hothersall, D (1997). Historia de la psicología. México: McGraw-Hill. Interamericana de México

56. Kant, I. (1788/2000). Crítica de la razón práctica. Madrid: Alianza.

57. May, R. (1974). Psicología existencial. En Millon, T., ob. cit., págs, 174-181. México: Interamericana.

58. Evans, R. (1987). Carl Rogers. En Evans, Los artífices de la psicología y el psicoanálisis, págs. 256-270. México: FCE.

59. Rogers, C. (1959/1974). Una teoría de la personalidad. En Millon, ob. cit., págs. 188193. México: Interamericana.

60. Lakatos, L. (1983). La metodología de los programas de investigación científica. Madrid: Alianza.

61. Linehan, M. (2Q:03). Manual de tratamiento de los trastornos de personalidad límite. Barcelona: Paidós Ibérica. 